\title{
STUDYING DENTINE CARIES IN THE FIRST PERMANENT MOLARS IN CHILDREN
}

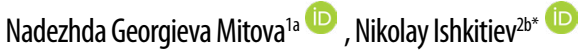 \\ 'Department of Pediatric Dentistry, Faculty of Dental Medicine, Medical University of Sofia, Sofia, Bulgaria \\ ${ }^{2}$ Department of Medical Chemistry and Biochemistry, Medical Faculty, Medical University of Sofia, Sofia, Bulgaria \\ ${ }^{a} \mathrm{DMD}, \mathrm{PhD}$, Assistant Professor \\ bDMD, PhD, Chief Assistant Professor
}

\section{ABSTRACT DOI: https://doi.org/10.25241/stomaeduj.2019.6(3).art.2}

Introduction: Caries in permanent teeth most often start from the occlusal surfaces of the first molars, soon after eruption at the age of six. At that point the occlusal surfaces are at risk due to the presence of many retentive areas.

Aim - To study the spread and characteristics of cavitated dentine caries in the first permanent molars after eruption.

Methodology: 351 children, distributed into two groups were subjected to the study: the first group - 6 to 9-year olds, and the second group - 10 to 12-year olds. The registration of the oral status was carried out with an epidemiological card for oral health assessment - brief bio, dental status and description of the cavitated carious lesions in the dentine. The clinical description of the D3 carious lesions present was determined according to the localization of the carious lesions (occlusal, approximal, cervical), the color and the consistency of the carious dentine, via the Bjørndal et al scale.

Results: The results of this study show that children aged 6 to 12 have on average

OPEN ACCESS This is an Open Access
article under the CC BY-NC 4.0 license.
Citation: Mitova NG, Ishkitiev N. Studying dentine
caries in the first permanent molars in children.
Stoma Edu J. 2019; $6(3)$ :170-176.
Received: August 06, 2019
Revised: August 22, 2019
Accepted: August 27, 2019
Published: August 29, 2019
*Corresponding author:
Chief Assistant Professor Nikolay Ishkitiev, DMD,
PhD, Address: Zdrave 2 str,, room 343, 1431 Sofia,
Bulgaria, Tel. / Fax: +359 885 108620,
e-mail: ishkitiev@gmail.com.
Copyright: $\odot 2019$ the Editorial Council for the
Stomatology Edu Journal.
three to four carious teeth. Dentine carious lesions D3 with occlusal localization in the first permanent molars are plausibly more numerous than the carious lesions with approximal and cervical localization. In the first permanent molars, the dentine carious lesions with occlusal localization are characterized by darker colors of carious dentine and a relatively hard consistency.

Conclusions: In the first permanent molars the more slowly progressing carious lesions are predominant.

Keywords: Caries; Dental decay; Dentine; Occlusal surfaces; Permanent first molar.

\section{Introduction}

Caries formation is a dynamic process of imbalances in the oral environment that lead to the development of carious lesions, on predisposed surfaces in the primary and permanent teeth in children [1]. The progression of the carious lesion may be influenced in its early stages of development by modeling the oral environment and remineralization [2-4]. Despite the indisputable successes and the increased scientific interest with respect to improving children's dental health, the problem of reducing the frequency and severity of caries remains relevant [5-7]. On a world scale, $60-90 \%$ of school-age children suffer from caries (WHO, 2012). The disease also leads to serious economic consequences for society as a whole [8]. According to the data from the last epidemiological study conducted in Bulgaria in 2011, approximately $71 \%$ of the six-year-old children in the country have caries, with the most frequently affected temporary teeth numbering three or four. In the 12-year-olds group, $79 \%$ of them had caries of the permanent teeth, with an average of three permanent teeth being affected, and in the 18 year-olds group the same held true for $92 \%$ of the teeth, with the number of affected permanent teeth reaching six. Every fourth 18-year-old already has one extracted tooth. Only $30 \%$ of the six-year-olds in the country are caries free, and with the 12-year-olds the percentage drops further down to $22 \%[6,7]$.

Caries in permanent teeth most often start from the occlusal surfaces of the first permanent molars, soon after their eruption at the age of six. At that point the occlusal surfaces are at risk due to the presence of many retentive areas. The mineralization of the enamel at that place is not complete. Difficulty in early diagnosing of the initial carious lesions present on the occlusal surfaces of the permanent first molars and the lack of regular prophylactic examination leads to the quick development of cavitated dentine lesions during the first years after eruption. This requires their early inclusion in the restoration cycle, and not infrequently leads to their early loss.

Raising awareness for the spread and characteristics of dental caries in the permanent first molars, conducting effective prophylactics or timely microinvasive treatment of already developed lesions could lead to a significant decrease of occlusal caries in children with a mixed dentition. 
ITable 1.Visual-tactile criteria. (Bjørndal et al.)

\begin{tabular}{|l|l|}
\hline \multicolumn{1}{|c|}{ Visual criteria - dentine color } & Tactile criteria (with probe) - dentine consistency \\
\hline black & $\begin{array}{l}\text { Code 1 (very soft) - the probe penetrates and peels parts of it } \\
\text { away easily; } \\
\text { Code 2 (soft dentine) - probe can easily penetrate and exit the } \\
\text { dentine; } \\
\text { Code 3 (moderately hard) - light resistance during probing; } \\
\text { Code 4 (hard dentine) - the probe moves over the dentine with } \\
\text { light brown } \\
\text { yellow } \\
\text { light yellow } \\
\text { Code 5 (hard non-carious) - soft squeaking and resistance } \\
\text { during probing. }\end{array}$ \\
\hline
\end{tabular}

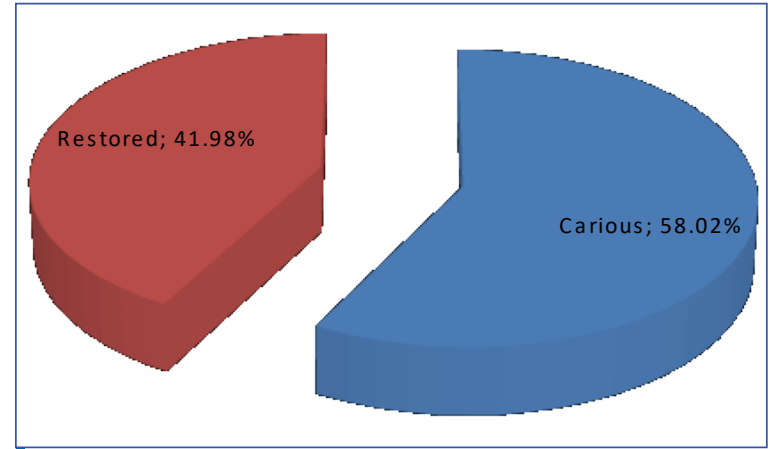

Figure 1. Ratio between carious and restored permanent first molars. $t=5,00 p<0,05$

Aim - To study the spread and characteristics of cavitated dentine caries in the permanent first molars, immediately after eruption.

\section{Tasks}

1. To study the general cariousness and the relative portion of occlusal caries in the permanent first molars in children aged $6-12$.

2. To provide a clinical description of the registered cavitated dentine carious lesions in the permanent first molars of the children tested.

\section{Materials and Methods}

351 children, distributed into two groups were the subject of the study, as follows: group one - 6 to 9-year-olds; group two - 10 to 12-year-olds. We had received an ethical approval from KENIMUS - Etical commission of the Medical University of Sofia 24/07.12.2018.

Registration of the oral status of the children was carried out with an epidemiological card for oral health assessment, which includes a brief biography, dental status and description of the cavitated carious lesions in the dentine present - D3 according to the locally adopted Peneva et al. classification [9]. All surfaces of a tooth were cleaned of debris and plaque, the teeth were dried using an air syringe and visually examined without magnification. If there were suspicious areas, then an explorer - a blunt probe (periodontal probe) was used to check for the surface texture and to remove plaque from fissures using a dredging motion.

The carious status of the children was diagnosed and registered in teeth with a D1b diagnostic threshold

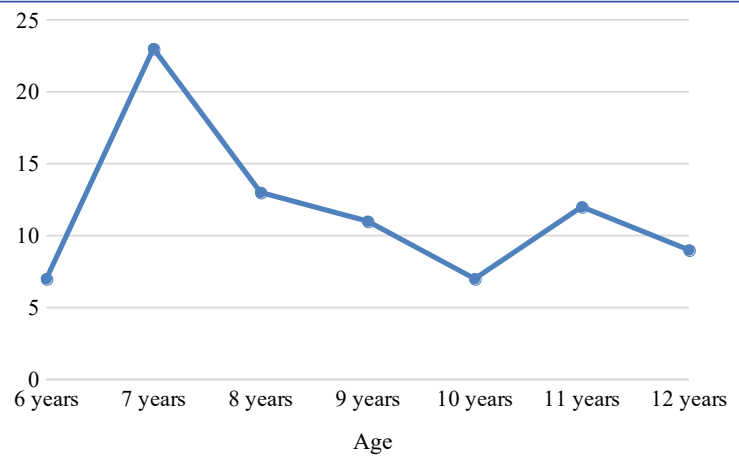

Figure 2. Spread of D3 lesions in first permanent molars.

- enamel carious lesion visible after drying. Further noted were D2, D3a, D3b and D4 carious lesions. The DMFT index was used, and while registering it, for the purposes of this study, DMF $(T+t)$ was also registered, due to the fact that part of the children were with a mixed dentition [9]. The fissure sealants were included in the number of restorations.

The clinical description of the D3 carious lesions present was determined according to the location of the carious lesions (occlusal, approximal, cervical), the color and consistency of the carious dentine, via the Bjorndal et al scale [10].

The statistical processing of the data was carried out with the statistical program SPSS (version 19, SPSS Inc. USA). A 95\% interval of plausibility $(p<0.05)$ was chosen as a level of significance at which the null hypothesis is rejected.

\section{Results}

\subsection{Cariousness of the children tested:}

- General cariousness

The results obtained in determining the cariousness - DMF $(T+t)$ of the children tested, are presented in the following table.

The results show that the general cariousness (DMF $(T+t)$ in all children is between three and four carious teeth. A plausible decrease in cariousness is observed in temporary teeth, due to their replacement, while an increase in cariousness is observed in permanent teeth with age $(p<0.05)$.

- Relative portion of carious and restored permanent first molars

The following diagram presents the results, obtained 
ITable 2. Cariousness of the children tested $-\mathrm{DMF}(\mathrm{T}+\mathrm{t})$ as grouped by ages.

\begin{tabular}{|c|c|c|c|c|c|}
\hline \multirow[b]{2}{*}{ Children gr. } & \multicolumn{2}{|c|}{ DMFT } & \multirow{2}{*}{$\begin{array}{c}\text { DMFt } \\
\begin{array}{c}\text { Mean } \pm \text { SD } \\
\text { (teeth) }\end{array}\end{array}$} & \multirow{2}{*}{$\begin{array}{c}\mathrm{DMF}(\mathrm{T}+\mathrm{t}) \\
\begin{array}{c}\text { Mean } \pm \text { SD } \\
\text { (teeth) }\end{array}\end{array}$} & \multirow[b]{2}{*}{ Ind t-test } \\
\hline & $\begin{array}{c}\mathrm{N} \\
\text { children }\end{array}$ & $\begin{array}{c}\text { Mean } \pm \text { SD } \\
\quad \text { (teeth) }\end{array}$ & & & \\
\hline $1^{\text {st }}$ gr. -6 to 9 & 201 & $0.60 \pm 0.87$ & $3.60 \pm 2.24$ & $4.20 \pm 2.31$ & $\begin{array}{ll}\mathrm{T}_{\mathrm{T}, \mathrm{t}}=-17.05 & (\mathrm{P}=0.00) \\
\mathrm{T}_{\mathrm{T}, \mathrm{T}+\mathrm{t}}=-22.78 & (\mathrm{P}=0.00) \\
\mathrm{T}_{\mathrm{t}, \mathrm{T}+\mathrm{t}}=-9.87 & (\mathrm{P}=0.00)\end{array}$ \\
\hline $2^{\text {nd }}$ gr. -10 to 12 & 150 & $2.42 \pm 1.76$ & $0.99 \pm 1.30$ & $3.42 \pm 1.74$ & $\begin{array}{ll}\mathrm{T}_{\mathrm{T}, \mathrm{t}}=6.80 & (\mathrm{P}=0.00) \\
\mathrm{T}_{\mathrm{T}, \mathrm{T}+\mathrm{t}}=-9.20 & (\mathrm{P}=0.00) \\
\mathrm{T}_{\mathrm{t}, \mathrm{T}+\mathrm{t}}=-10.87 & (\mathrm{P}=0.00)\end{array}$ \\
\hline Ind T-test & \multicolumn{2}{|c|}{$\mathrm{T}=-12.73 \quad \mathrm{P}=0.00$} & $\mathrm{~T}=12.7 \mathrm{P}=0.00$ & $T=-1.61 \quad P=0.11$ & \\
\hline
\end{tabular}

ITable 3.Distribution of the carious lesions in the permanent first molars.

\begin{tabular}{|c|c|c|c|c|c|c|c|c|c|c|}
\hline \multirow{2}{*}{$\begin{array}{l}\text { Diag. T-hold } \\
\text { Children group }\end{array}$} & \multicolumn{2}{|r|}{ D1b } & \multicolumn{2}{|r|}{ D2 } & \multicolumn{2}{|r|}{ D3 } & \multicolumn{2}{|r|}{ D4 } & \multicolumn{2}{|c|}{ total } \\
\hline & $\mathrm{n}$ & $\% \pm S p$ & $\mathrm{n}$ & $\% \pm S p$ & $\mathrm{n}$ & $\% \pm S p$ & $\mathrm{n}$ & $\% \pm S p$ & $\mathrm{n}$ & $\%$ \\
\hline $1^{\text {st }} \mathrm{gr}-6$ to 9 & 12 & $12.90 \pm 3.48$ & 27 & $29.04 \pm 4.71$ & 54 & $58.06 \pm 5.12$ & 0 & & 93 & 100 \\
\hline $2^{\text {nd }} \mathrm{gr}-10$ to 12 & 73 & $40.11 \pm 3.63$ & 76 & $41.76 \pm 3.66$ & 28 & $15.38 \pm 2.67$ & 5 & $4.12 \pm 1.34$ & 182 & 100 \\
\hline total & 85 & & 103 & & 82 & & 5 & & 275 & 100 \\
\hline T test & \multicolumn{2}{|c|}{$\mathrm{I}=5.41$} & \multicolumn{2}{|c|}{$I=2.14$} & \multicolumn{2}{|c|}{$\mathrm{I}=7.39$} & & & & \\
\hline
\end{tabular}

in determining the relative portion of carious and restored permanent first molars of the children tested. The data in the diagram show that the carious permanent first molars are plausibly predominant over the restored ones in both age groups $(p<0.05)$. The data gathered in determining the severity of the registered carious lesions in the first molars are presented in the table 3 . The data presented in the table show that in the permanent first molars in the first age group, D1b take up only $12.9 \%$, D2 carious lesions are $29 \%$, and over a half (58\%) of the registered carious lesions are irreversible - D3 in the period immediately after eruption of the examined teeth $(p<0.05)$. In the second age group the portion of reversible carious lesions plausibly increases, while the irreversible ones plausibly decrease, which is probably due to the restoration of the cavitated lesions $(p<0.05)$. The higher relative portion of irreversible carious lesions in the children of the first age group (6-9 years) could be explained by the specificities of the carious pathology of the fissures of these teeth in cases where adequate preliminary prophylactics are lacking. The data gathered in this study regarding the spread of cavitated dentine carious lesions (D3) in first molars according to the age of the children are presented in the following diagram. The graph shows that the peak of registered D3 carious lesions in the sixth teeth of the children tested can be observed as early as after the first or second year of their eruption. A quick progression of the occlusal caries is present in the seven to eight year period and development of D3 carious lesions. Past eight years of age a significant decrease in the cases of D3 lesions is observed, probably due to an increase in the number of restored teeth.
3.2. Clinical description of the registetred dentine carious lesions (D3) in the permanent first molars of the children tested.

- Localization of the carious lesions

The data are presented in the table 4.

Between the ages of 6 and 12 , the D3 carious lesions with occlusal localization in the first molars are $72 \%$ and are significantly more than those with approximal (14.6\%) and cervical (13.4\%) localization in both age groups $(p<0.05)$. As the children grow in age, the caries with occlusal, approximal and cervical localization remain within close parameters $(p>0.05)$. The anatomical peculiarities of the permanent first molars are a primary risk factor for the onset of an occlusal caries, immediately after eruption. They have a highly characteristic occlusal surface (narrow and deep fissures), thin to non-existent enamel at the bottom of the fissures, significantly lower mineralization, insufficient self-cleaning of these surfaces, absence of established oral hygiene habits and lack of motivation for early control. Early diagnostics in such cases is more difficult which leads to the development of cavitated dentine carious lesions in the molars [6,9].

- Color and consistency of the carious lesions

The color of the carious dentine of the D3 lesions in the permanent first molars is predominantly black, followed by dark brown carious dentine, while the lowest is the number of registered $D 3$ carious lesions which are light brown in color $(p<0.05)$.

The predominant darker colors in the carious dentine may be due to delayed pigments and this is an indicator for a slower developing carious process, which is conducive to microinvasive treatment. The aim is to further slowdown or arrest the development 
ITable 4. Distribution of D3 lesions in permanent first molars according to localization.

\begin{tabular}{|c|c|c|c|c|c|c|c|c|}
\hline \multirow[b]{2}{*}{ Children group } & \multirow{2}{*}{$\begin{array}{l}\text { total } \\
\mathrm{n}\end{array}$} & \multicolumn{2}{|c|}{ occlusal } & \multicolumn{2}{|c|}{ approximal } & \multicolumn{2}{|c|}{ cervical } & \\
\hline & & $\mathrm{n}$ & $\% \pm s p$ & $\mathrm{n}$ & $\% \pm s p$ & $\mathrm{n}$ & $\% \pm s p$ & \\
\hline $1^{\text {st }} \mathrm{gr}-6$ to 9 & 54 & 40 & $74.1 \pm 5.96$ & 8 & $14.8 \pm 4.83$ & 6 & $11.1 \pm 4.28$ & $\begin{array}{l}\mathrm{T}_{1,2}=6.08 \\
\mathrm{~T}_{1,3}=6.66 \\
\mathrm{~T}_{2,3}=0.56\end{array}$ \\
\hline $2^{\text {nd }} \mathrm{gr}-10$ to 12 & 28 & 19 & $67.9 \pm 8.83$ & 4 & $14.3 \pm 6.61$ & 5 & $17.8 \pm 7.24$ & $\begin{array}{l}\mathrm{T}_{1,2}=3.50 \\
\mathrm{~T}_{1,3}=3.19 \\
\mathrm{~T}_{2,3}=0.34\end{array}$ \\
\hline total & 82 & 59 & $72.0 \pm 4.96$ & 12 & $14.6 \pm 3.90$ & 11 & $13.4 \pm 3.76$ & $\begin{array}{l}\mathrm{T}_{1,2}=6.08 \\
\mathrm{~T}_{1,3}=6.66 \\
\mathrm{~T}_{2,3}=0.56\end{array}$ \\
\hline & & \multicolumn{2}{|c|}{$t_{2,3}=0.58$} & \multicolumn{2}{|c|}{$t_{2,3}=0.06$} & \multicolumn{2}{|c|}{$t_{2,3}=0.80$} & \\
\hline
\end{tabular}

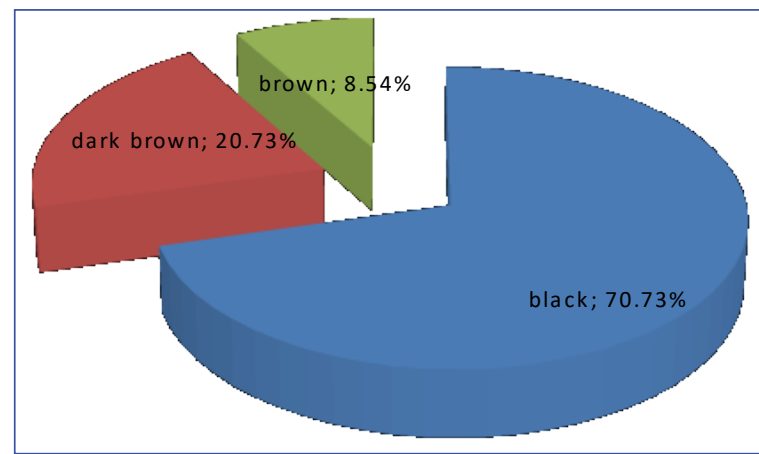

Figure 3. Color of the carious dentine in the first molars with D3 carious lesions. Pearson Chi Square $=12,468$ Sig $=0,000$

of the dentine caries and provide conditions for activating the natural defence mechanisms of the pulp-dentine complex.

The diagram shows that in over $3 / 4$ of the cases the consistency of the carious dentine of the registered D3 carious lesions is that of a moderately hard dentine $(76 \%)$, while the remaining $1 / 4$ of cases are distributed equally between soft $(12 \%)$ and very soft dentine $(12 \%)(p<0.05)$.

The data show that the consistency of the carious dentine of the $\mathrm{D} 3$ carious lesions in permanent teeth is predominantly code 3 - moderately hard $(p<0.05)$. Soft and very soft consistency (code 2 and code 1 ) of the carious dentine is found in a smaller percentage of the cases of the registered D3 carious lesions. If we adopt the notion that the consistency of the carious dentine depends on the speed of the carious process and is indicative of this, we could reach the conclusion that in the D3 carious lesions of the first permanent molars, registered in this study, the caries with a slower development speed are predominant, which confirms the conclusion reached regarding the color of the dentine.

- The study of the interdependency of the research parameters - color, consistency DMFT+t - is presented via the Pearson correlation index at a plausibility level of $p<0.05$ and $p<0.01$. The data in the table show that the color of the carious dentine correlates with the consistency and the DMFT+t

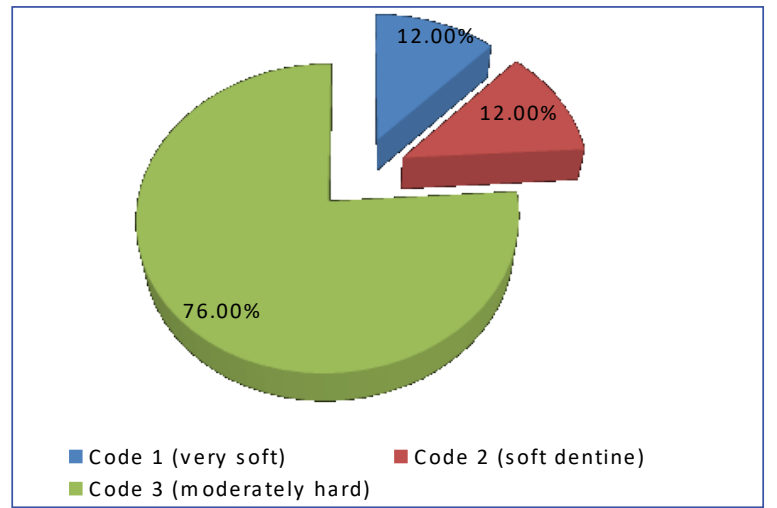

Figure 4. Consistency of the dentine in the D3 carious lesions of the first molars. Pearson Chi Square $=14,732$ Sig $=0,000$

index. The data are supported by high statistical plausibility $(p<0.01)$. Higher values of the DMFT+t index are observed in the children with darker and relatively hard carious dentine in the cavitated dentine lesions. In the first permanent molars of the children covered in this study, the cases of relatively hard, dry carious dentine with dark coloration are predominant.

\section{Discussion}

The results of this study show that children between aged 6 to 12 have on average three to four carious teeth. The general cariousness (DMFT+t) is higher between the ages of 6-9 (4.20), while in older children it decreases slightly (3.42). The results of this study show that the ratio between carious and restored teeth of the children studied changes in the separate age groups, with the cases of carious teeth (D) decreasing at the expense of increasing the relative proportion of restored teeth $(F)$ as the age of the children increases.

The data gathered in this study match that of the last national epidemiological study of the spread of dental caries in children in 2011, which showed that in six-year-old children between three to four carious teeth can be found, and three carious teeth in 12 -year-olds. The epidemiological study conducted in the Ruse region in 2010 shows that six-year-old children have an average of six carious teeth $[6,7]$. 
ITable 5.Correlation between color, consistency and DMFT in the children studied.

\begin{tabular}{|l|c|c|c|}
\hline & \multicolumn{3}{|c|}{ Pearson Correlation index } \\
\hline indicators & color & const. & DMFT+t \\
\hline color & & $-0.767^{* *}$ & $-0.682^{* *}$ \\
\hline consistency & $-0.767^{* *}$ & & $0.673^{* *}$ \\
\hline DMFT+t & $-0.682^{* *}$ & $0.673^{* *}$ & \\
\hline
\end{tabular}

A2008 study by M. Peneva shows that DMFT is 4.3, which includes only dentine carious lesions. If we add enamel caries, which are reversible, the data will show an average of seven carious teeth [11].

The first permanent molars erupt in early childhood and carry a maximal occlusal load as the main chewing teeth. They are among the most affected form of dentine caries due to their morphological and functional characteristics, which is the motivation behind this study of the spread and characteristics of the dentine caries in this tooth group.

The higher relative portion of irreversible carious lesions, established in this study, of first permanent molars in the children of the first age group (6-9 year old) could be explained by the specificities of the carious pathology of the fissures of these teeth in cases where adequate preliminary prophylactics are lacking. The stages conducive for non-operative treatment in these instances pass quickly and can easily be missed, which leads to the development of dentine caries in the permanent teeth immediately after their eruption, with a high risk of affecting the highly exposed pulp. As to avoiding potential complications in the treatment of such carious lesions, the efforts of a number of authors are dedicated toward the development and application of methodologies for minimally invasive operative treatment of dentine lesions, with the aim of optimally preserving the structures of the recently erupted permanent children's teeth [12-15].

Similar to our study some authors have reported high scores of cavitated dentine carious lesions in children in Canada (between $38 \%$ to $44.1 \%$ ) and Thailand - in 3-year-olds [16,17].

The levels of cavitated dentine carious lesions increase with age and they remain problematic in adults [18]. The cohort study reported that over a period of 38 years, an annual increase in number of tooth surfaces affected by cavitated dentine carious lesions [19]. The results of this study show that D3 carious lesions with occlusal localization in the first permanent molars are plausibly more numerous than the carious lesions with approximal and cervical localization in both age groups. According to a study, the occlusal surfaces are only $6 \%$ of all dental surfaces, while occlusal caries account for $60 \%$ of all caries. It is considered that this is due primarily to the plaque retentive anatomy of these surfaces [20]. According to studies, most frequent are occlusal caries in molars, followed by approximal caries in molars, while least carious are the approximal surfaces of the front teeth $[21,22]$.
The rapid development of occlusal caries in the dentine of newly erupted permanent molars has steered numerous researchers in the direction of applying treatment methodologies that provide an optimally non-invasive excavation, leading to a minimal loss of hard dental structures. Careful excavation would allow for the preservation of dentine, which is partially demineralized, but with preserved regeneration capabilities, which are highly expressed in the permanent teeth of children [23,24]. This study has concluded that in the first molars, the dentine carious lesions with occlusal localization are characterized by darker colors of carious dentine and a relatively hard consistency. The results of this study confirm the idea that darker color and harder dentine consistency are probable indicators of a more slowly developing carious lesion, while lighter color and softer consistency - of a faster developing carious lesion [25].

In our study we found that the newly erupted permanent first molar evince high prevalence of cavitated carios lesion, which means that there is a significant risk of affecting the highly exposed pulp. The features of the carious process in these teeth makes them especially appropriate for applying the minimal invasive methods of treatment. The analysis of the results shows that in the first permanent molars the more slowly progressing carious lesions are predominant. This circumstance has been the basis for trying to develop methodologies for a minimallyinvasive treatment of these carious lesions, with data being found in scientific literature in recent years about a number of authors working in this direction [26-28]. The aim is to develop alternative methods and methodologies for a treatment which will lead to an additional slowdown and/or arrest of the carious process in the dentine and provide conditions for the activation of the natural defense mechanisms of the pulp-dentine complex [29,30]. The prevalence of occlusal dentinal caries lesion in the newly erupted permanent molars and their early inclusion in the cycle of "caries-restorationreplacement of restoration" draws our attention to the need of an application of new therapeutic methods of minimally-invasive treatment. The aim is to ensure the preservation of integrity of the pulp and apply the biological approach.

\section{Conclusions}

1. Dentine carious lesions D3 with occlusal localization in the permanent first molars are plausibly more numerous than the carious lesions 
with approximal and cervical localization;

2. In the permanent first molars, the dentine carious lesions with occlusal localization are characterized by darker colors of carious dentine and a relatively hard consistency;

3. The more slowly progressing carious lesions are predominant in the permanent first molars.

\section{Author Contributions}

NM: contributed to formulating the concept, protocol, data gathering, analysis and interpretation of the data. NI: contributed to the analysis, interpretation of the data and critically revised the manuscript. Both authors agree to be accountable for the content of the work.

\section{Acknowledgments}

None.

\section{References}

1. Fejerskov O. Changing paradigms in concepts on dental caries: consequences for oral health care. Caries Res. 2004;38(3):182-191. [Full text links] [CrossRef] [PubMed] Google Scholar Scopus 2. Bader JD, Shugars DA, Bonito AJ. Systematic review of selected dental caries diagnostic and management methods. J Dent Educ. 2001;65(10):960-968

[Full text links] [CrossRef] [PubMed] Google Scholar Scopus

3. Huysmans MC. New diagnostic approaches: promise or reality? In: Splieth CH. Revolutions in pediatric dentistry. New Malden, Surrey (UK): Quintessence Publishing Co., Ltd; 2011. 1-10.

4. Lussi A, Hibst R, Paulus R. DIAGNOdent: An optical method for caries detection. J Dent Res. 2004;83 Spec No C:C80-83.

[Full text links] [CrossRef] [PubMed] Google Scholar Scopus

5. Kondeva V. [Occlusal caries in childhood - epidemiological and clinical studies.] [Bulgarian]. PhD Thesis. Plovdiv, BG: Medical University of Plovdiv; 2008.

6. Peneva $M$, Rashkova $M$, Doitchinova L. [Epidemiology of dental caries in children and adolescents in Bulgaria at different diagnostic threshold.] [Bulgarian]. Problems of Dental Medicine. 2007;33(2):37-46

7. Rashkova M, Ribagin L, Doganova Tsv, Aleksieva V. [Oral diseases of children from the Rousse region - epidemiological studies, part of the National program for prevention of oral diseases in children aged 0-18.] [Bulgarian]. Problems of Dental Medicine. 2011:37(2):17-28

8. Aas JA, Griffen AL, Dardis SR, et al. Bacteria of dental caries in primary and permanent teeth in children and young adults. J Clin Microbiol. 2008; 46(4):1407-1417.

[Full text links] [Free PMC Article] [CrossRef] [PubMed] Google Scholar Scopus

9. Peneva M. [Dental caries in the 21st century] [Bulgarian]. Sofia, BG: East-West; 2008.

10. Bjørndal L, Larsen T, Thylstrup A. A clinical and microbiological study of deep carious lesions during stepwise excavation using long treatment intervals. Caries Res. 1997;31(6):411-417.

[Full text links] [CrossRef] [PubMed] Google Scholar Scopus

11. Peneva M. The path to transition from operative to non-operative preventive treatment of dental caries. SCD Dissertation. Sofia, BG: Medical University of Sofia; 2008. [Bulgarian].

12. Bjørndal L. Buonocore Memorial Lecture. Dentin caries: Progression and clinical management. Oper Dent. 2002;27(3):211-217.

[PubMed] Google Scholar Scopus

13. Bjørndal L. Indirect pulp therapy and stepwise excavation. J Endod. 2008;34(7 Suppl):S29-S33.

[Full text links][CrossRef] [PubMed] Google Scholar Scopus

14. Mickenautsch $S$. An introduction to minimum intervention dentistry. Singapore Dent J. 2005; 27(1):1-6.

Google Scholar Scopus
15. Banerjee A. Minimal intervention dentistry: part 7. Minimally invasive operative caries management: rationale and techniques. Br Dent J. 2013;214(3):107-111.

[Full text links] [CrossRef] [PubMed] Google Scholar Scopus

16. Borsatto MC, Corona SA, Dibb RG, et al. Microleakage of a resin sealant after acid-etching, Er:YAG laser irradiation and air-abrasion of pits and fissures. Clin Laser Med Surg. 2001;19(2):83-87.

[CrossRef] [PubMed] Google Scholar Scopus

17. Dennison JB, Straffon LH, Smith RC. Effectiveness of sealant treatment over five years in an insured population. J Am Dent Assoc. 2000;131(5):597-605.

[Full text links] [PubMed] Google Scholar Scopus

18. Nobre Dos SM, Rodrigues LK, Peres RC, et al. Relationships between occlusal or free-smooth and approximal caries in mixed dentition. Acta Odontol Scand. 2005;63(5):308-313.

[CrossRef] [PubMed] Google Scholar Scopus

19. Balooch M, Habelitz S, Kinney JH, et al. Mechanical properties of mineralized collagen fibrils as influenced by demineralization. J Struct Biol. 2008;162(3):404-410.

[Full text links] [Free PMC Article] [CrossRef] [PubMed] Google Scholar Scopus

20. Banerjee A. Applications of scanning microscopy in the assessment of dentine caries and methods for its removal. PhD thesis. London, UK: University of London; 1999.

21. Bjørndal L, Larsen T. Changes in the cultivable flora in deep carious lesions following a step-wise excavation procedure. Caries Res. 2000;34(6):502-508.

[Full text links] [CrossRef] [PubMed] Google Scholar

22. Li T, Zhai X, Song F, et al. Selective versus non-selective removal for dental caries: a systematic review and meta-analysis. Acta Odontol Scand. 2018;76(2):135-140.

[Full text links] [CrossRef] [PubMed] Google Scholar Scopus 23. Marsh PD. Are dental diseases examples of ecological catastrophes? Microbiology. 2003;149(Pt 2):279-294.

[Full text links] [CrossRef] [PubMed] Google Scholar

24. Mjör IA, Ferrari M. Pulp-dentin biology in restorative dentistry, Part 6: Reactions to restorative materials, tooth restoration interfaces, and adhesive techniques. Quintessence Int. 2002;33(1):35-63.

[PubMed] Google Scholar

25. Hargreaves KM, Geisler T, Henry M, Wang Y. Regeneration potential of the young permanent tooth: what does the future hold. J Endod. 2008;34(7 Suppl):S51-S56.

[Full text links] [CrossRef] [PubMed] Google Scholar Scopus

26. Bjørndal L, Mjör IA. Pulp-dentin biology in restorative dentistry, Part 4: Dental caries--characteristics of lesions and pulpal reactions. Quintessence Int. 2001;32(9):717-736.

[PubMed] Google Scholar Scopus 
Nadezhda Georgieva MITOVA

DMD, PhD, Assistant Professor

Department of Pediatric Dentistry

Faculty of Dental Medicine

Medical University of Sofia

Sofia, Bulgaria

Nadezhda Georgieva Mitova graduated from the Medical School in 2006 and Dental Medicine in 2011. Since 2012 she has been Assistant Professor in the Department of Pediatric Dentistry, Faculty of Dental Medicine, Medical University of Sofia, Sofia, Bulgaria. She has specialized in Pedodontics. Her scientific interests are focused on dental caries and profilactics of oral diseases.

\section{Ouestions}

\section{What is the most common location of caries in the permanent first molars?}

口a. Approximal;

ab. Cervical;

ac. Occlusal;

ad. Other.

\section{Which of the following most fully and accurately describes the causes of occlusal caries in the first permanent molars?}

$\square$ a. Deep and retentive fissures; unsatisfactory oral hygiene habits;

ab. A thin and slightly mineralized layer of enamel; unsatisfactory oral hygiene habits; difficult diagnosis; ac. Deep and retentive fissures; a thin and slightly mineralized layer of enamel; unsatisfactory oral hygiene habits; availability of timely and adequate prevention;

$\square d$. Deep and retentive fissures; a thin and slightly mineralized layer of enamel; difficult diagnosis; unsatisfactory oral hygiene habits; lack of timely and adequate prevention.

\section{What is the characteristic of carious dentine in the occlusal caries of the permanent first molars?}

$\square$ a. Dark and relatively hard dentine;

b. Dark and soft dentine;

ac. Light and soft carious dentine;

$\square$ d. Light and relatively hard dentine.

\section{Which type of lesions prevails according to the speed and nature of the carious process in the occlusal caries of the permanent first molars?}

a. Rapidly progressing carious lesions;

b. Slowly progressing carious lesions;

ac. Both;

ad. Neither.

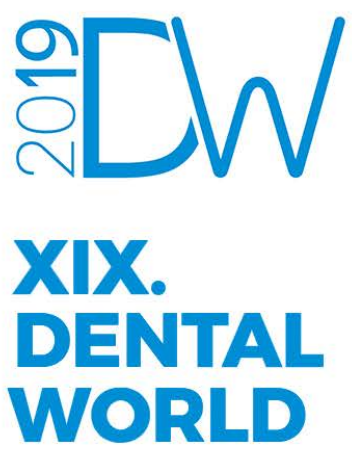

10-11-12 October 2019

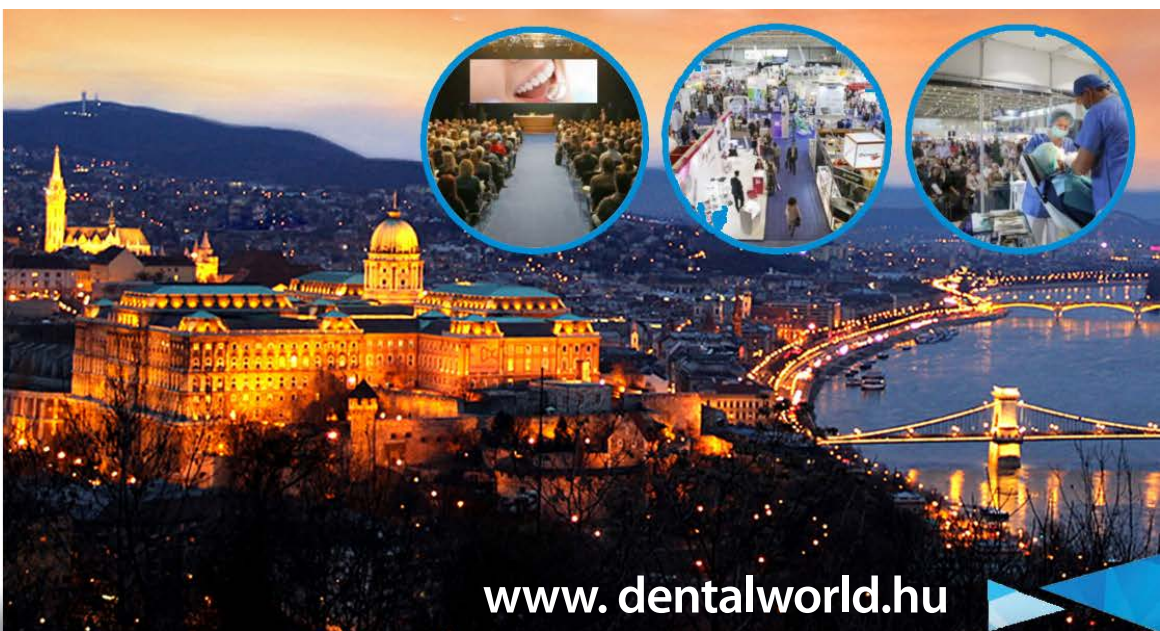

